\title{
Ciudadanía digital. Entre la novedad del fenómeno y las limitaciones del concepto
}

\section{Digital Citizenship. Between the novelty of the phenomenon and the limitations of the concept}

\author{
Natal, Alejandro, Mónica Benítez y Gladys Ortiz (coords.) \\ (20I4), CiUdadAnía digital, uam Iztapalapa-uam Lerma-Juan Pablos \\ EDITOR, MÉXICO, 272 PP., ISBN 978-607-28-O I62-2, UAM,
} ISBN 978-607-7 I I-202-0.

\section{La novedad del fenómeno digital}

Basta una palabra, una foto, un video o un símbolo para que millones de usuarios den un "clic" al tópico "me gusta" o se pronuncie seguido de un hastag, muchas veces una tendencia de tipo temporal que responde a un asunto de moda o de consumo particular en el trending topic; pero cuando involucra a un asunto público explota en el ciberespacio y se vuelve incontrolable, agresivo y veloz, flujos de eventos que penetran y se apropian la vida íntima de las colectividades.

A finales del siglo xx y principios del Xxi el encuentro entre las personas y el mundo digital se intensificó transformando radicalmente la realidad y permeando en el ámbito político, económico, social o cultural, puesto que se constituyó un nuevo espacio de interacción-actuación que es compartido y se reinscribe constantemente (De Certeau, 2000), el internet. Tras la emergencia de ciudadanos en el mundo que emprenden prácticas políticas y sociales a través del uso de internet y distintas tecnologías de la información y la comunicación (TIC) para hacer valer sus derechos, realizar demandas sociales, incidir en la agenda pública, exigir transparencia en procesos político-electorales, rendición de cuentas y construir acción colectiva en busca del bien común, se ha puesto especial atención en el fenómeno de los medios digitales.

En el caso de México el ejercicio de la ciudadanía digital es aún un proceso lento, entre otras causas debido a que la mayoría de la población en el país carece de acceso a la red, sin embargo, cada vez más usuarios se suman al uso de nuevos medios digitales; en este sentido lo novedoso del fenómeno es que se está ejerciendo ciudadanía digital bajo peculiares condiciones y circunstancias que lo hacen un asunto polémico por sus 
beneficios y sus perjuicios, por sus virtudes y sus vicios, por sus avances y limitaciones en la sociedad.

Esto ha generado que internet y las nuevas TIC sean objeto de estudios interdisciplinarios, volviéndose para intereses de ciertas colectividades un aspecto de las políticas de Estado tales como su regulación, control, accesibilidad y costo. En la actualidad son diversos los esfuerzos académicos y las discusiones que buscan conceptualizar, analizar y reflexionar sobre este tipo de experiencias que se están suscitando vía la web 2.0 (Mossberger, Tolbert y Mc Neal, 2008; Robles, 2009, por mencionar algunas referencias).

Para enriquecer estas reflexiones se suman avances de investigación y análisis plasmados en la obra Ciudadanía digital, la cual constituye una referencia obligada para aquellos interesados en el tema, puesto que incluye distintas perspectivas de estudio que buscan evidenciar cómo la sociedad se apropia de lo público para construir alternativas de ejercer ciudadanía. Sus aportaciones son importantes porque se intenta mostrar cómo las características de los nuevos medios están construyendo o no efectivamente más participación y nuevas formas de ejercer la ciudadanía.

\section{Del contenido y estructura de la obra Ciudadanía digital}

Ciudadanía digital es una obra colectiva coordinada por Alejandro Natal, Mónica Benítez y Gladys Ortiz cuya intención es la de enriquecer estudios sociales, políticos, económicos y culturales relacionados con los medios digitales; para lograr este propósito, los investigadores de la UAM Unidad Lerma reúnen variados análisis de tipo exploratorio que giran en torno a tres preguntas fundamentales: ¿las nuevas tecnologías ofrecen herramientas a los activistas que pueden socializar para construir un colectivo en el mundo real? ¿Generan los medios digitales nuevas condiciones para que cada vez más ciudadanos participen en temas públicos? ¿Es la participación en medios digitales una novedad que perderá vigencia o, por el contrario, es una transformación definitiva de las formas en que nos involucramos en lo público?

Para intentar responder estos cuestionamientos se presentan diversos casos de estudio y discusiones organizadas en nueve capítulos. En el primer capítulo se trata el concepto de Ciudadanía digital y se examina el papel de los medios digitales como herramientas al servicio de los ciudadanos; asimismo, se analiza el distanciamiento entre gobernantes y gobernados, la pérdida de legitimidad y la desconfianza del ciudadano hacia las autoridades, lo que se vuelve un problema político porque éste pierde interés en participar en los problemas que aquejan a la sociedad.

Los autores del capítulo sostienen que la desconfianza se manifiesta de manera efectiva a través de medios como las redes sociales virtuales; 
algunos casos abordados son el movimiento de los indignados en España y “\#Yosoy 132" en México. Ambos movimientos constituyen manifestaciones de la contrademocracia (según los fundamentos de Pierre Rosanvallon hay tres formas de expresión: poderes de control, las formas de obstrucción y puesta a prueba a través de un juicio) que aportan a la construcción de una nueva ciudadanía.

En este orden de ideas, se subraya que para ser ciudadano digital "se deben cumplir al menos tres condiciones: acceso a internet, conocimiento en el manejo de las herramientas de internet y reconocimiento del usuario de la utilidad de internet para la interacción política” (p.38). Al final de este capítulo se advierte que el ejercicio de la ciudadanía digital no precisamente asegura una mayor calidad de la democracia, pero si puede potencializar la participación ciudadana en asuntos de la esfera pública en el mundo real.

A lo largo del segundo capítulo, Marcos López discute que las redes sociales virtuales (por ejemplo Facebook o Twitter) han recreado la forma en que socializamos al funcionar como mecanismos de acicalamiento, pavoneo o chisme para el establecimiento de redes de cohesión y confianza, así como el acceso a información relevante que determinados grupos sociales necesitan. Además se resalta que las redes sociales, como elemento de cambio en la evolución de la comunicación interpersonal, facilitan a las personas el acceso a asuntos públicos que pueden no estar en los medios, generando en el receptor sentimiento de cercanía y la impresión de que su participación contribuirá al cambio. También se expone el potencial de las redes sociales de reducir el tiempo, la energía y los recursos que los individuos dedican a discutir temas de interés colectivo, construir opinión, desarrollar propuestas, medir la inmediatez de la respuesta a las mismas y construir comunidades.

Dentro del tercer capítulo se plantea el tema de la brecha digital, con lo cual se presenta un breve panorama estadístico sobre la distribución, disponibilidad, acceso y uso que se les da a las herramientas de internet en México; según datos de 2011, la brecha digital en este país se encuentra por debajo del promedio de la región de América Latina, situándose en el décimo primer lugar de 20 en cuanto al número de población con acceso a internet, mientras que países como Argentina, Chile y Uruguay ocupan los primeros tres lugares respectivamente.

Para la realización del estudio, el autor Manuel Lara privilegió dos fuentes de información: el Módulo de Condiciones Socioeconómicas de la Encuesta Nacional de Ingresos y Gastos de los Hogares y el Módulo sobre Disponibilidad y Uso de Tecnologías de la Información de los Hogares para el año 2010. A partir de estas fuentes se establecieron datos para diferenciar entre el campo y la ciudad (el uso de medios digitales es un 
fenómeno eminentemente urbano porque en el campo de la mayoría de la población no tiene acceso a internet), así como las desigualdades que se dan en términos de ingreso y género (la ciudadanía digital es un fenómeno también exclusivo para el sector de la población con mayores ingresos).

Conjuntamente se buscó responder qué sectores de la población tienen capacidad para utilizar estos nuevos medios, y hasta qué punto internet y las redes sociales son utilizados, o por el contrario, son medios reservados para una minoría (el sesgo por género determina que la mujer tiene menos acceso a las nuevas tecnologías). La discusión también se enfoca en si el uso de internet está ligado a sectores sociales ya educados o, por el contrario, hay señales de democratización en el otorgamiento de este servicio.

El cuarto capítulo, titulado "Ciudadanía digital y Social Media Revolution", consiste en reflexionar sobre el cambio de paradigma en la interacción gobierno y sociedad y en la participación política de la sociedad civil; específicamente, el capítulo elaborado por Jorge Castillo tiene como finalidad estudiar la influencia que han tenido las redes sociales sobre el comportamiento de algunos actores sociales involucrados en procesos político-electorales y el desarrollo de las campańas políticas en el mundo, particularmente en México.

Las campañas electorales de candidatos y ciudadanos han encontrado en las redes sociales y en los social media nuevas formas de interacción y participación, pues desde internet se convocan manifestaciones, se promueven candidatos, se establecen críticas abiertas y sin censura, y se emiten opiniones en asuntos de interés público (por ejemplo durante las elecciones federales en 2012, las protestas, críticas y rechazo a la campaña política de Enrique Peña Nieto, candidato del Partido Revolucionario Institucional y actual presidente de México); ante este tipo de eventos se plantean algunas interrogantes, ¿cuál es la relación que existe entre el pluralismo político e internet? ¿Cuál es la reacción de los partidos políticos y de la sociedad civil en regímenes democráticos? ¿Cómo actúan o reaccionan los regímenes autoritarios hacia estas nuevas prácticas?

En el quinto capítulo, Alejandro Natal y Mauricio Ibarra intentan mostrar aspectos sobresalientes de ciertas experiencias en las que Twitter funciona como herramienta para la acción colectiva en México. Algunas de estas experiencias han sido el movimiento por "el voto nulo", movimiento "internet necesario", movimiento de la "guardería ABC", movimiento "Yo soy Twit Terrorista", entre otros. Los principales fundamentos desarrollados en este capítulo revelan que gracias a Twitter se han manifestado distintos tipos cambios: 1) la articulación entre individuos con intereses similares pero que estaban atomizados; 2) Twitter ha permitido que ciudadanos dispersos accedan a información relevante de una forma simple; 3) ha creado puentes de comunicación entre ciudadanos y fun- 
cionarios, quienes, sin conocerse, entran en contacto y debaten aspectos de una política pública; 4) ha sido parte de un asunto coyuntural que, probablemente, no habría detonado de manera intensa si no fuera por las necesidades de participación que tienen los ciudadanos y porque los usuarios son individuos con una politización y niveles de información superiores a la medida. Asimismo, resulta relevante que en la mayoría de los casos expuestos, los medios tradicionales fueron impactados por Twitter, también se muestra tangiblemente que es posible construir comunidades en torno de una tendencia.

Entre los hallazgos más representativos sobre Twitter se encuentra "el hecho de que puede servir como medio de comunicación e información relevante; Twitter reconoce las asimetrías no sólo de información sino también de participación, ya que facilita el involucramiento de los ciudadanos y hace que la relación con la autoridad sea más horizontal. Paralelamente Twitter es dependiente de la coyuntura política y social y se ha vuelto referencia obligada para los medios masivos que lo ubican no sólo como un medio, sino como una fuente de información y divulgación" (p. 142).

En este sentido, Twitter sigue siendo un fenómeno propio de la clase media urbana (la minoría); la mayoría es una sociedad con problemas estructurales de acceso limitado a las TIC y tiene una educación muy tradicional y limitada en cuanto a la crítica y el uso de nuevas tecnologías, por ello es poco probable que critique el desarrollo en proceso masivo de reflexión.

Pese a esto, los autores del capítulo aseguran que "la comunidad que usa Twitter es valiosa, en la medida que representa una ciudadanía activa que se moviliza, busca y difunde información de manera intensa, se apropia de ella, debate y cuestiona a las instituciones y políticas públicas, al tiempo que demanda la rendición de cuentas" (p. 142). Esta situación obliga y presiona a las autoridades para escuchar a sus ciudadanos.

En el sexto capítulo se visualiza a las redes sociales como un catalizador de la acción política al propiciar que comunidades virtuales puedan vincularse -a través de los post de los muros, tuits y las invitaciones de amigos conocidos- a causas que les requieren. En esta intención se abordan dos casos de acción política para el empoderamiento y el ejercicio de ciudadanía plena de grupos excluidos "En defensa del migrante centroamericano" y "En defensa de Wirikuta"; el análisis se realiza "con base en el contenido de los sitios de Facebook (el perfil de cada manifestación, el tipo de información que aporta y las acciones que se promueven) para saber qué tipo de acción articulan y si ésta tiene un impacto en las agendas políticas de los gobiernos local, estatal y nacional” (p. 147). 
De igual forma se busca observar si se utilizan otras tecnologías que complementan o refuerzan el activismo con la solidaridad o la creación artística. Este capítulo resulta interesante en la medida que problematiza los conceptos de ciudadanía digital, comunidades virtuales en relación con la acción social, empoderamiento e inclusión social. Posteriormente, se explora si la amplitud de las acciones emprendidas por estas las manifestaciones, "Defensa del migrante" y "Defensa de Wirikuta" han permitido que algunas de sus demandas entren en la agenda pública, y si su acción política perdura en el tiempo y se consolida en el empoderamiento de grupos sociales excluidos.

Jóvenes, redes sociales y participación política: una crónica del movimiento social "\#Yosoy132" en México se presenta como una propuesta diferente en el desarrollo del séptimo capítulo. Este trabajo se compone de una muestra de videos, notas informativas y datos obtenidos de internet, está constituido por fuentes privilegiadas de información.

Los autores hacen hincapié en cómo se gestó el movimiento juvenil a partir de una serie de eventos que tuvieron como punto de partida el uso de las redes sociales y la incapacidad de ciertos actores políticos mexicanos que no respondieron adecuadamente a sus demandas, se lo configura como un movimiento visible compuesto de ciudadanos críticos interesados en los asuntos de la esfera pública.

Una de las virtudes de este trabajo es que se expone al movimiento 132 más allá de actos de protesta o de una serie de marchas y, que sus integrantes -en su mayoría- jóvenes se hacen visibles como sujetos activos, participativos e interesados en el acontecer de país y del mundo, dejando a un lado el estigma de que ser joven es sinónimo de indiferencia social.

A pesar de que se han emitido todo tipo de juicios valorativos sobre este movimiento, los autores del capítulo muestran tanto las limitaciones como los alcances logrados por los participantes en cuanto a su colaboración vía internet y otros medios digitales y su involucramiento con los asuntos políticos electorales. Así pues, el movimiento 132, gestado durante el proceso electoral del 2012, constituye una muestra de que las redes sociales virtuales actúan como catapultas del descontento social y como herramientas útiles en la generación y propagación de un movimiento mediante plataformas de discusión, foros, blogs, entre otras.

En el octavo capítulo se discute cómo internet está transformando las formas de participación no convencionales online y está revolucionando las formas de acción colectiva, haciendo especial énfasis en el hacktivismo. A pesar de que los autores advierten que aún hay escasez de bibliografía sobre este fenómeno, el hacktivismo se muestra desde dos posturas: por un lado, como una actividad ilegal porque viola la privacidad de la sociedad, y por otro, como una estrategia novedosa y no institucionalizada de 
expresión política. Para los autores de este trabajo, "el hacktivismo es un tipo de participación política no convencional y en ocasiones, subrayan, una forma de desobediencia civil cuyas tácticas y repertorios son no violentos y no lucrativos, que persiguen fines públicos y que están basados en internet o la creación de herramientas digitales que puede tener ambigüedad legal” (p. 207).

Para dar mayor solidez a sus argumentos, los autores del capítulo sobre hacktivismo intentan construir una historia del fenómeno mediante una serie de sucesos en el mundo, tal es el caso de Wikileaks, evento que obligó a los gobiernos a crear sistemas de inteligencia para monitorear a los activistas sociales. Del mismo modo, comentan que en México una de las primera acciones de hacktivistas fue la del grupo Anonymous, que el 15 de septiembre de 2011 hakeó al menos cuatro páginas del gobierno federal mexicano para impedir el acceso a los internautas, en protesta por la estrategia del gobierno federal en la lucha contra el narcotráfico, la cual algunos ciudadanos percibieron como equivocada.

En este capítulo se muestra cómo la inmediatez, ubicuidad y bajo costo de las nuevas tecnologías de información y comunicación han provocado cambios importantes en la forma de participación política, aunque también se discute que, en la acción colectiva tradicional, internet facilita y ayuda en términos de organización, movilización y transnacionalización.

En una reflexión más profunda, se da cuenta de que el fenómeno del hacktivismo ha permitido construir comunidades de ciudadanos digitales interesados en ciertos asuntos públicos que articulan nuevas estrategias políticas y espacios democráticos; de igual manera se ha reformulado nuestra manera de pensar la política y la forma en la que se trata de incidir en la toma de decisiones. Si bien el fenómeno del hacktivismo se está extendiendo se considera que no sustituye a la acción colectiva tradicional, mas bien, podría pensarse como complementaria.

El último capítulo, desarrollado por Mónica Benítez, describe un proyecto artístico, tecnológico y social que lleva funcionando casi 10 años con resultados interesantes en varias partes del mundo, dicho proyecto es denominado Megafone.net una pieza artística cuyo concepto fue diseñado en 2003 por el artista catalán Antoni Abad. Este proyecto es el primero a nivel mundial en utilizar teléfonos celulares y comunidades excluidas en un proyecto artístico y se basó únicamente en mostrar fotos, videos y mensajes localizados a través de la página de internet multimedia para su difusión.

Megafone.net ha desarrollado hasta el año 2010, doce proyectos en distintas partes del mundo con algunos colectivos como: los taxistas de México (2004), los jóvenes gitanos en Leida y León (2005), las prostitutas en Madrid (2005), los inmigrantes nicaragüenses en San José de 
Costa Rica (2006), las personas con movilidad reducida en Barcelona y Ginebra en (2006, 2008), los motoboys en Sao Paulo (2007), los desplazados inmovilizados en Colombia (2008), los refugiados saharauis en Argelia (2009), entre otros. "Ha sido diseñado para que grupos, colectivos, asociaciones o comunidades especificas proyecten, narren y describan su visión de la realidad, contrastándola como los estereotipos preestablecidos" (p. 224-225).

La intención de este trabajo es mostrar, a través del estudio de un caso, la enorme complejidad que implica utilizar la red para compartir arte con otras culturas digitales y la capacidad de producción de conocimiento que de ello se puede derivar. Si se piensa que la cultura digital artística está conformada por un sinfín de elementos, agentes y colectivos se puede entender la complejidad del fenómeno, ya que se requiere tecnología, artistas, usuarios, técnicos, programadores, empresas, instituciones, centros culturales, museos, etcétera. En esta misma idea, se considera que la cultura digital artística es complementaria al ejercicio de la Ciudadanía digital porque a través de innumerables expresiones artístico-tecnológicas se pueden construir nuevas comunidades y forjar nuevas identidades digitales que sin duda son actores activos y que puede determinar el futuro de la sociedad a la cual pertenecemos. Hasta aquí hemos intentado presentar las ideas centrales que contiene la obra de referencia.

\section{La limitación del concepto y del ejercicio de la Ciudadanía digital}

La redefinición de la forma en la que los ciudadanos participan, discuten, interactúan y reflexionan sobre nuestro papel como ciudadanos en el mundo contemporáneo, hace pensar que el término de Ciudadanía digital puede alcanzar diferentes dimensiones mediante distintos tipos de tecnologías, incluyendo no sólo a medios tradicionales como la radio o la televisión sino además otro tipo de plataformas y herramientas digitales aún no desarrolladas; en este sentido se vuelve un concepto con diversas limitaciones puesto que así como la tecnología se vuelve obsoleta, el concepto puede también serlo al no tomar en cuenta tipos particulares de tics para apropiarse de la realidad.

El concepto de ciudadanía digital puede limitarse considerablemente si deja de tomarse en cuenta información y datos que aporten nuevos elementos; en el libro se expusieron estudios de casos exitosos, pero también existen aquellos que no lograron articularse o tener vigencia, por lo cual podemos decir que las limitaciones no sólo se encuentran en la conceptualización del fenómeno sino también en la realidad, en el ejercicio de la ciudadanía digital.

En este orden de ideas, resulta complejo conceptualizar los diversos problemas e implicaciones que se plantean con la convergencia tecnoló- 
gica, algunos de ellos son la construcción o no de una mejor democracia, la potenciación del poder ciudadano, la situación económica de los desconectados y, también, saber si el ejercicio de una ciudadanía digital es una moda o un cambio definitivo en la sociedad para participar su entorno político.

Bajo este estado de cosas, Alejandro Natal, Mónica Benítez y Gladys Ortiz sugieren que "las personas que intentan ejercer la ciudadanía digital tienen que contar con nuevas capacidades como: a) involucrar a una mayor masa crítica de ciudadanos que genere acción política distribuida y abierta a más sectores de la población; b) crear opinión pública en otros ciudadanos, ya que la participación de algunos puede ser mecánica o de baja demanda e intensidad, y donde no siempre el participante está realmente involucrado en una causa o si únicamente constituye un acto para matar el tiempo; c) realizar reflexión social y política que realmente sustente un cambio de largo aliento; d) producir y compartir bienes comunes en beneficio de la sociedad, entre otros" (p. 269).

Sin estas capacidades el ciudadano limitaría seriamente el potencial de los medios digitales para promover cambios profundos en la realidad. De la misma forma, los coordinadores de la obra reconocen que el concepto de ciudadanía digital aún carece de un cuerpo teórico preciso y suficiente que permita entender de forma más amplia este nuevo fenómeno, así como desarrollar metodologías que permitan abordarlo de forma más integral.

En esta reflexión, el alcance del concepto de ciudadanía digital hasta ahora sólo ha permitido distinguirla del ejercicio de la ciudadanía tradicional, no obstante, hay otras áreas de oportunidad para realizar investigaciones que los mismos coordinadores del libro señalan como "temas de investigaciones pendientes, entre ellos se encuentra el determinar si ¡¡ślo aquellos que ejercen su ciudadanía en el mundo real son capaces de utilizar de manera efectiva las herramientas del mundo actual o si, se han encontrado las herramientas para apropiarse de lo público? ¿Hasta qué punto el slacktivismo hace reflexionar y tener mayor conciencia de los asuntos públicos? ¿Qué plataformas sirven, para qué y cómo evolucionan los usos que los ciudadanos deciden darles? ¿Realmente las nuevas tecnologías pueden convertirse en herramientas que generen identidad y acción colectiva o únicamente promueven el consumo a nivel mundial?” (268).

Finalmente, como se ha podido apreciar en sus innumerables reflexiones, la obra Ciudadanía digital deja abierta la discusión para abordar aquellos aspectos e implicaciones que no se tuvieron en cuenta con respecto al uso de internet y nuevas tecnologías para ejercer una mejor ciudadanía. 


\section{Bibliografía}

De Certeau, Michel (2000), "Relatos de espacio", en Certeau, Michel, La invención de lo cotidiano, ITESO-UIA, México, pp. 127-142.

Mossberger, Karen, Caroline Tolbert y Ramona Mc Neal (2008), Digital Citizenship, the Internet, Society, and Participation, мIт Press, Cambridge.

Robles, José Manuel (2009), Ciudadanía digital, introducción a un nuevo concepto de ciudadanos, Editorial UOC, Barcelona.

Recibida: 24 de febrero de 2015. Aceptada: 13 de marzo de 2015.

Walter Ortega-Gabriel Universidad Autónoma Metropolitana, unidad Lerma Correo-e: walterortegagabriel@yahoo.com.mx

Walter Ortega-Gabriel. Mexicano. Maestro en estudios regionales por el Instituto de Investigaciones Científicas Dr. José María Luis Mora; realizó estudios en sociología por la Facultad de Ciencias Políticas y Sociales de la Universidad Autónoma del Estado de México, ha sido colaborador de investigación en El Colegio Mexiquense A. C. Actualmente se encuentra adscrito al Departamento de Procesos Sociales de la Universidad Autónoma Metropolitana Unidad Lerma. Sus líneas de investigación son desarrollo social, territorio y sociedad civil; participación ciudadana, democracia y políticas públicas. Entre sus publicaciones recientes destacan, en coautoría, "Bienes comunes y cooperación. Explorando a las asociaciones: el caso de Fundaciones Comunitarias de México", en Memorias del XIV Congreso Anual de Investigación sobre el Tercer Sector, Centro Mexicano para la Filantropía-Universidad Anáhuac México Norte, México, pp. 323-343 (2014); "Fundación comunitaria del Bajío: estudio de caso sobre actores locales en procesos de desarrollo social", en Alejandro Natal y Humberto Muñoz Grandé (coords), Fundaciones comunitarias en México: nuevos aportes para el Desarrollo Local, Fundación para el Desarrollo del Tercer Sector A.C.-INDESOL, México, pp.119-151 (2015). 